\title{
Revisão por Pares: \\ O Coração das Revistas Científicas
}

\section{Peer Review: The Heart of Scientific Journals}

Helena Donato ${ }^{1}$

Autor Correspondente:

PALAVRAS-CHAVE: Revisão por Pares; Revistas

KEYWORDS: Peer Review; Periodicals as Topic

\section{O QUE É O PEER REVIEW?}

A revisão por pares (peer review) também designada por arbitragem científica, é uma componente fundamental para a prática e progresso da Medicina e é essencial para o sucesso de uma revista científica.

O sistema de peer review começou em meados do século XVII com as primeiras revistas científicas, quando os cientistas decidiram que antes de publicar um artigo, deviam pedir a opinião a colegas a trabalhar na mesma área. Esta lógica advém do facto de que a exposição do trabalho à crítica dos pares permitirá identificar falhas e melhorar a qualidade do material publicado. ${ }^{1} \mathrm{O}$ primeiro registo de peer review é de 1665 por Henry Oldenburg, o editor fundador da Philosophical Transactions da Royal Society of London. A primeira publicação revista por pares foi Medical Essays and Observations publicada pela Royal Society of Edinburgh em 1731.

Assim, o peer review (PR) é usado há mais de três sécu- $\operatorname{los}^{2}$ para manter os padrões de qualidade da publicação e representa um papel importante na comunicação científica, é o pilar da publicação científica. Mas o processo de PR só começou a ser largamente usado por todas as revistas científicas no século $X X$, quando o número de manuscritos submetidos aumentou exponencialmente, para garantir que os trabalhos publicados são rigorosos, éticos, transparentes e encaixam no âmbito e qualidade da revista. ${ }^{3}$ Na sua essência o PR consiste em perguntar a peritos o quão importante e bom é um trabalho, se é adequado para publicação e como pode ser melhorado.

O International Committee of Medical Journals Editors (ICMJE) define o peer review como: "Peer review is the critical assessment of manuscripts submitted to journals by experts who are not part of the editoral staff". ${ }^{4}$

O objetivo do PR é garantir que um manuscrito fornece uma contribuição ética, original e com qualidade para a literatura científica, identificando os melhores trabalhos submetidos a uma revista, fornecendo uma avaliação 
justa e imparcial, e corrigindo erros ou deficiências na comunicação científica antes da publicação. O PR ajuda o editor a tomar decisões acerca da publicação de um manuscrito e aumenta a qualidade científica do que é publicado.

O PR atua como um filtro para seleção e como um mecanismo de controlo da qualidade, devendo ser o mais imparcial possível.

\section{TIPOS DE PEER REVIEW}

A maioria das revistas médicas pratica o peer review cego (single-blinded) em que a identidade dos revisores não é revelada aos autores. Este anonimato significa que a contribuição do revisor para o autor melhorar o seu trabalho não é reconhecida. ${ }^{5}$

Algumas revistas usam o PR duplamente cego (double-blinded) em que o revisor e autor não conhecem a identidade um do outro, numa tentativa de redução do viés, pensando que os revisores podem ser influenciados, positiva ou negativamente, pelo estatuto ou reputação dos autores ou pelas afiliações institucionais. Mas este tipo de revisão tem como grandes desvantagens não se ter consciência se existem conflitos de interesse e o autor pode acabar por ser identificado pelo contexto e pelas referências. $^{5}$

Nos últimos 15 anos têm sido experimentados novos modelos de peer review, o open, o post-publication e o collective.

Tornar todo o processo de revisão público pode ter vantagens e desvantagens. No open PR, revisor e autor conhecem a identidade um do outro. A vantagem deste tipo de PR é que se torna um processo transparente em que nada é escondido, mas pode haver uma grande dificuldade em recrutar revisores dispostos a dar a opinião de uma forma aberta, pode inibir a crítica e pode levar a animosidade, represálias e constrangimento de relacionamentos. Por exemplo, um revisor júnior pode sentir-se inibido a fazer uma revisão rigorosa para não afrontar um colega sénior, temendo que possa ter repercussões negativas no futuro, nomeadamente em promoções, avaliações ou candidaturas. ${ }^{5}$

O open PR é um processo transparente numa perspetiva ética e menos sujeito a viés ou adulteração de ideias e/ou dados por revisores, assim como atrasos deliberados ou indevidos na entrega das revisões.

\section{O PAPEL DO EDITOR-CHEFE}

O editor-chefe de uma revista científica é sempre uma figura eminente e com anos de experiência.
O processo de avaliação dos manuscritos submetidos às revistas tem duas fases:

\section{Revisão editorial: o editor primeiro avalia a qualidade geral das submissões, o cumprimento das normas da revista e adequação ao âmbito e aos leitores da revista.}

\section{Peer review}

Muito embora o processo de PR possa diferir ligeiramente de revista para revista, tem sempre uma estrutura similar. O manuscrito é submetido à revista e o editor-chefe após uma avaliação inicial decide se o artigo deve ser enviado para revisão por pares ou rejeitado de imediato. Normalmente o editor convida mais do que um revisor a avaliar o trabalho.

Ao contrário do que muitos autores pensam, os editores não procuram razões para rejeitar os manuscritos, procuram antes razões para aceitá-los. O editor-chefe é considerado a autoridade suprema de uma revista, exercendo poder absoluto para decidir o que publicar. Assim, a rejeição de manuscritos é uma das suas responsabilidades mais importantes. Rejeitando trabalhos, um editor define o conteúdo editorial da revista, pois os revisores aconselham mas não tomam decisões de aceitar ou rejeitar um trabalho. A decisão final de aceitar ou rejeitar é do editor, mas claro que esta decisão é fortemente baseada nas recomendações dos revisores.

Algumas vezes, a impaciência dos autores em obterem uma decisão editorial para os seus trabalhos e a procrastinação dos revisores tornam a tarefa do editor muito difícil.

\section{O PAPEL DOS REVISORES}

As revistas científicas confiam no PR para publicarem manuscritos de alta qualidade, ou seja, confiam no esforço de revisores voluntários que são escolhidos com base na sua experiência, competência e na disponibilidade para avaliar a qualidade de um manuscrito.

Os revisores são os guardiões da publicação científica, filtrando o que tem pouca qualidade científica, têm um duplo papel: Manuscrito merece ser publicado? Papel consultivo: fornecer crítica construtiva (ajudar a fazer um manuscrito melhor).

"Review unto others as you would have them review unto you".

O que o Editor espera do Revisor?

- Avalie a originalidade, validade, clareza e utilidade (se os resultados já foram publicados; se há plágio);

- Identifique eventuais falhas;

- Dê feedback construtivo aos autores com sugestões para melhoria; 
- Comente de forma objetiva e imparcial;

- Envie resposta atempada.

Um bom revisor é: Competente; consistente; confiável; responsável; conhecedor do processo científico; íntegro; imparcial e pontual.

\section{PARA QUÊ SER REVISOR?}

No mundo da publicação científica há falta de revisores. Se publicou um artigo numa revista científica então provavelmente será convidado a rever artigos futuros com um tema similar.

A maioria das revistas não fornece treino sobre como fazer a revisão, não há praticamente recompensa, pouco ou nenhum reconhecimento e consome tempo. A grande maioria dos revisores tem de desempenhar esta tarefa fora de um dia normal de trabalho e tem que completar a revisão dentro de prazos apertados.?

O que pode uma revista fazer para melhorar a revisão e ter revisores?

- Publicar anualmente a lista dos revisores;

- Publicar um guia para a análise crítica;

- Organizar sessões formais de treino em peer review;

- Fazer workshops em conferências sobre redação e revisão científica.

Se os revisores realizam uma tarefa quase invisível e que não são compensados pelo tempo e esforço então porque o fazem?

Por uma questão de cidadania científica e porque existem alguns benefícios em ser revisor:

- Melhorar o pensamento crítico;

- Aumentar o conhecimento e consciência, fortalecendo a reputação profissional;

- Fazer parte do processo de publicação, aprendendo aspetos que ajudarão na preparação dos seus próprios manuscritos;

- Oportunidade para aprender e manter-se atualizado;

- Quem quer publicar, deve estar disponível para rever;

- Revisões frequentes - convite para Conselho Editorial;

- Ser revisor é um reconhecimento implícito da competência e profissionalismo.

Um revisor nunca se deve esquecer de incluir o seu trabalho como revisor em qualquer esforço de promoção ou na escrita do currículo.

\section{COMO REVER UM MANUSCRITO?}

Não há nada pior para um editor-chefe do que receber uma revisão que unicamente indica "bom manuscrito". Mas a revisão por pares é uma arte para a qual não há treino formal. Não é ensinada durante a educação médica pré ou pós-graduada.

Antes de aceitar rever, um perito deve questionar-se se conhece bem a área ou os métodos descritos para produzir uma boa revisão e se tem tempo disponível para realizar a revisão dentro do tempo que Ihe é indicado, sabendo que um revisor em média demora entre 4 a 5 horas a rever um artigo. ${ }^{8}$

Se um potencial revisor tem hesitações nestes dois pontos, não deve aceitar fazer a revisão.

Outra questão importante são os potenciais ou reais conflitos de interesses. Se tiver um potencial conflito de interesses, um revisor não tem de declinar o convite mas deve informar o editor de todas as relações que podem ser vistas como potencial conflito de interesses, e que podem influenciar inapropriadamente (viés) as suas ações, para que ele possa tomar uma decisão.

Conflito de interesses ocorre quando a objetividade de um indivíduo é potencialmente comprometida. Conflitos de interesses que surgem a partir de relações pessoais ou financeiras, competição académica e paixão intelectual não são raros em ciência. A confiança pública no processo de PR e a credibilidade dos artigos publicados dependem, em parte, em quão bem são manuseados os conflitos de interesses durante a escrita, peer review e decisão editorial.

Um revisor deve manter a confidencialidade do manuscrito e nunca deve contactar diretamente os autores, exceto se tiver permissão do editor. Não pode ser influenciado pela origem do manuscrito, nacionalidade, religião, sexo ou outras características do autor. Deve fornecer uma avaliação honesta e crítica do manuscrito com comentários acerca dos pontos fortes e fracos do manuscrito, assim como sugestões para melhorar a sua qualidade. Assim, o relatório do revisor tem dois objetivos: ajudar o editor a decidir o que fazer com o manuscrito; ajudar os autores a melhorá-lo antes da publicação, fornecendo uma crítica construtiva. É muito importante que o revisor trate o manuscrito que está a avaliar da mesma maneira que quer que os seus manuscritos sejam tratados.

Não há a revisão perfeita, mas existem algumas orientações para melhorar o PR:

Se aceita a revisão deve submetê-la a tempo. Se por acaso não consegue cumprir o deadline estabelecido informe o editor. 
A revisão deve ser feita considerando o seguinte processo:

1. Ler o manuscrito todo antes de fazer uma crítica detaIhada. Dessa primeira leitura deve responder a questões mais gerais: os autores fornecem informação nova e atualizada? O manuscrito está bem redigido, é claro e conciso? Como pode ser melhorado?

2. A revisão do texto deve incluir: um parágrafo de sumário descrevendo o objetivo do manuscrito e a nova ou atualizada contribuição. Se tem dificuldade em escrever este parágrafo é porque a qualidade do manuscrito não é grande.

3. Identificar eventuais falhas.

4. Feedback detalhado e construtivo para cada secção. Os revisores devem comentar cada secção mesmo que esteja boa.

5. Comentar de forma objetiva e imparcial. Começar por um comentário positivo ao autor fornece encorajamento.

6. Avaliar se o resumo sumaria corretamente o manuscrito e se está estruturado de acordo com as instruções aos autores.

7. Avaliar a necessidade e a clareza das tabelas e figuras incluídas.

8. Avaliar a relevância das referências e a ausência de referências importantes. As referências devem ser sempre as mais recentes e fornecem o suporte apropriado ao conteúdo do manuscrito.?

9. Enviar resposta atempada sem prolongar desnecessariamente o processo de revisão.

10.Os comentários devem ser construtivos e numerados $(1,2,3 \ldots$ etc.) para que os autores possam facilmente responder.

11. Não incluir as recomendações quanto ao destino do manuscrito nos comentários aos autores, só devem ser enviadas ao editor. Estas recomendações podem ser: aceite tal como está; revisões minor; revisões major; rejeição sem hipótese de ressubmissão; rejeição com hipótese de ressubmissão, mas com melhorias, mas sem garantia de aceitação. Em quase todas as revistas um artigo com revisões minor é aceite para publicação.

Notificar de imediato o editor-chefe se encontrarem irregularidades:

- Preocupações sobre aspetos éticos do trabalho;

- Semelhança substancial entre o manuscrito e outros trabalhos já publicados - duplicação/salami;
- Suspeita de má conduta científica - plágio; fraude; fabricação.

- website da EQUATOR ${ }^{10}$ é um extraordinário recurso com informação preciosa para revisores. Tem quase tudo o que é necessário saber para adequadamente rever um manuscrito. Recomenda-se ativamente que os revisores usem as diretrizes-chave para a revisão constantes no EQUATOR:

- Randomized controlled trials (RCTS): CONSORT guidelines;

- Systematic reviews and meta-analyses: PRISMA guidelines;

- Observational studies: STROBE guidelines;

- Diagnostic accuracy studies: STARD guidelines;

- Quality improvement studies: SQUIRE guidelines;

- Case Reports: CARE guidelines.

\section{RESPOSTA AOS REVISORES}

Como deve um autor lidar com o relatório dos revisores?

- Lê-lo e falar com um supervisor;

- Distanciar-se uns dias para acalmar;

- Fazer as alterações sugeridas;

- Quando envia o trabalho revisto, enviar uma resposta aos revisores, mencionando como levou em consideração os comentários;

- Se não concordar, explicar porquê;

- Se achar que os revisores não estão a ser justos, pedir uma segunda opinião.

Na resposta dos autores aos revisores a estrutura adequada é copiar os comentários dos revisores para um documento Word e responder cada comentário, pois todos os comentários devem ser respondidos ponto por ponto, listar cada comentário na íntegra, seguido pelas respostas. ${ }^{11}$

- Sugerimos o formato:

Revisor 1 comentário 1:

Resposta:

Enviar ao editor o manuscrito revisto com alterações efetuadas sinalizadas e o documento Word com as respostas aos comentários.

\section{CRÍTICAS AO PEER REVIEW}

O PR baseia-se essencialmente na confiança nos pares, mas como é um processo humano é propenso a erros e 
limitações. Por isso não surpreende que algumas vezes seja vulnerável a violações éticas, ineficiente, tendencioso, inadequado, algumas vezes até corrupto e uma tentação para plagiadores.

Os autores podem indicar quem não querem que reveja o manuscrito, com quem têm algum conflito de interesses ou que antecipam que fornecerão comentários potencialmente negativos.

O processo de PR pode facilmente ser corrompido por comportamentos antiéticos dos revisores como o plágio ou roubo de ideias, avaliação enviesada por conflitos de interesses, conservadorismo e penalização da inovação (exclusão de ideias que vão contra a corrente dominante), viés em relação a alguns autores, especialidades, instituições ou nacionalidades tanto a favor como contra, não deteção de falhas graves, inabilidade para detetar plágio, fraude e outros tipos de má conduta científica ou até bloqueio do trabalho com atrasos extremos e desnecessários para atrasar a publicação.

Contudo, estes eventos são raros e podem ocorrer mesmo em revistas de elevado prestígio e muito embora seja um processo imperfeito, a comunidade científica na sua grande maioria considera-o um processo valioso e o meIhor sistema disponível.

\section{REJEIÇÃO DO MANUSCRITO}

Rejeição não significa que o trabalho não seja bom - as revistas não podem publicar tudo o que recebem.

Quando um autor recebe um feedback negativo deve gerir emoções não respondendo de imediato, mas sim uns dias depois de ultrapassada a fase inicial de desânimo (é normal!); é vantajoso analisar as razões da rejeição. A decisão irá por e-mail do editor para o autor correspondente. Se o manuscrito foi rejeitado, os autores, podem 1) recorrer da decisão do editor por e-mail, mencionando que o manuscrito deve ser reconsiderado (mas é melhor não criar grandes expetativas); 2) rever substancialmente o manuscrito e submetê-lo novamente como um novo manuscrito; ou 3) submeter o manuscrito a outra revista (provavelmente a melhor opção).

\section{RAZÕES DE REJEIÇÃO ${ }^{5}$ :}

\section{Assunto}

- Desadequado para a revista

- Ausência de uma mensagem importante para o público-alvo

- Timing também pode ser um fator de rejeição. Até artigos de grande qualidade podem ser rejeitados se vá- rios artigos sobre o mesmo tópico forem submetidos num curto período de tempo ou se for submetido com um atraso, durante o qual os métodos ou conclusões se tornaram obsoletos devido ao aparecimento de novos estudos

- Investigação que não traz nada de novo à literatura existente

\section{Dados}

- Avaliação estatística incompleta ou inapropriada

- Interpretação excessiva dos resultados

- Tamanho da amostra insuficiente

- Resultados errados ou inconsistentes

- Discussão e conclusão fracas

- Conclusões não compatíveis ou injustificadas perante os resultados

- Problemas no método de pesquisa são responsáveis pela rejeição de $70 \%$ dos artigos

Cobertura

- Significado questionável

- Validade questionável - o estudo não examinou um tema científico importante

- Muito exaustivo

- Falta de originalidade

Tamanho

- Demasiado grande - informação a mais

- Demasiado pequeno - pouca informação

Apresentação

- Má organização

- Uso ineficaz de ilustrações

- Erros gramaticais e de ortografia

- Linguagem pobre ou incompreensível

- Não cumprimento das Instruções aos Autores

\section{CONCLUSÃO}

Neste primeiro número de 2017, a Gazeta Médica reconhece a importante contribuição de um grupo invisível cujo trabalho não é compensado nem divulgado, mas que é fundamental para a qualidade científica e ética da revista, os revisores.

Cada indivíduo listado forneceu um serviço aos seus colegas, ajudando a melhorar os seus manuscritos. No- 
meando os revisores é a forma que a revista tem de reconhecer os indivíduos que foram essenciais para a missão da revista, sem a sua generosidade a revista não podia realizar o seu trabalho.

O processo de revisão por pares tem sido o coração da publicação científica e a qualidade e segurança da literatura médica dependem deste processo. Tem sido alvo de muitas críticas ao longo dos anos, mas apesar das apreensões e desconfianças, o peer review tem resistido e ainda ninguém foi capaz de sugerir uma alternativa válida.

O sistema de avaliação pelos pares é muitas vezes comparado à democracia: "it is a very poor system, but better than all others". ${ }^{12}$

CONFLITOS DE INTERESSE: Os autores declaram a inexistência de conflitos de interesse na realização do trabalho.

FONTES DE FINANCIAMENTO: Não existiram fontes externas de financiamento para a realização deste artigo.

CONFLICTS OF INTEREST: The authors declare that they have no conflicts of interest.

FINANCIAL SUPPORT: This work has not received any contribution, grant or scholarship.

\section{REFERÊNCIAS}

1. Donato H, Marinho RT. Acta Médica Portuguesa and peer-review: quick and brutal! Acta Med Port. 2012;25:261-2.

2. Carvalho MS, Travassos C, Coeli CM. The value of peer review. Cad Saude Publica. 2014;30:1-2.

3. Hadi MA. Fake peer-review in research publication: revisiting research purpose and academic integrity. Int J Pharm Pract. 2016;24:309-10.

4. International Committee of Medical Journals Editors [consultado em 2 Janeiro 2017]. Disponível em: http://www.icmje. org/.

5. Donato H. A a Z da Comunicação Médica: Tips \& Tricks. São Mamede do Coronado: Bial; 2014.

6. Dutta MJ. The ten commandments of reviewing. Health Commun. 2006;20:197-200.

7. Riley BJ, Jones R. Peer review: acknowledging its value and recognizing the reviewers. Br J Gen Pract. 2016;66:629-30.

8. Kovanis M, Porcher R, Ravaud P, Trinquart L. The global burden of journal peer review in the biomedical literature: strong imbalance in the collective enterprise. PLoS One. 2016;11:e0166387.

9. Brandon D, McGrath JM. Conducting a Peer Review: Novice or Expert. Adv Neonatal Care. 2015:15:365-6.

10. EQUATOR Network [consultado em 30 Dezembro 2016]. Disponível em: http://www.equator-network.org/.

11. Kotsis SV, Chung KC. Manuscript rejection: how to submit a revision and tips on being a good peer reviewer. Plast Reconstr Surg. 2014;133:958-64.

12. Smith R. Peer Review: a flawed process at the heart of science and journals. In: The Trouble with Medical Journals. London: The Royal Society of Medicine Press; 2011. p.83-96. 